\title{
Pupil size and reactivity following hydroxypropyl methylcellulose and sodium hyaluronate
}

\author{
J Eason, H C Seward
}

\begin{abstract}
Aims-A prospective randomised clinical trial was set up to compare the effect of hydroxypropyl methylcellulose (Ocucoat) and sodium hyaluronate (Healonid) on pupil size and reactivity following their use in cataract surgery.

Methods-Pupil measurements were recorded before and 6 weeks after surgery. Results-There was no significant difference between the two groups with respect to pupil size $(p=0.69$, Mann-Whitney $U$ test) nor with respect to reactivity $(p=0.99$, Fischer's exact test). Ninety six per cent of the surgery was performed using phacoemulsification.

Conclusion-This trial suggests that both viscoelastic materials have similar effects on the pupil after their use in cataract surgery.
\end{abstract}

(Br f Ophthalmol 1995; 79: 541-543)

Hydroxypropyl methylcellulose (HPMC) solution has been used as a viscoelastic material in ophthalmic surgery since 1977 , initially to coat intraocular lenses before insertion ${ }^{1}$ and later as a $2 \%$ solution to maintain the anterior chamber. ${ }^{2}$ It has been shown in many clinical series to be a safe viscoelastic material. . $^{3-6}$ However, Tan and Humphrey ${ }^{7}$ recently reported that $16.7 \%$ of eyes operated on using HPMC developed a non-reactive semidilated pupil whereas no eyes receiving sodium hyaluronate (Healonid) developed this complication. This had not previously been reported.

We had been using commercially available HPMC (Ocucoat) since December 1992 on a doctors and dentists exemption scheme and had not observed this as a complication. We therefore set up a prospective randomised clinical trial of Ocucoat and Healonid to examine pupil size and reactivity before and 4-6 weeks after cataract surgery. The aim of the study was to evaluate the effect of the two different viscoelastic substances, Healonid and Ocucoat on pupil size and reactivity following their use in cataract surgery.

Croydon Eye Unit, Thornton Heath, Surrey

$\mathrm{J}$ Eason

H C Seward

Correspondence to:

Miss H C Seward,

Croydon Eye Unit,

33 Mayday Road,
Thornton Heath, Surrey

CR7 7YE.

Accepted for publication

10 January 1995

\section{Subjects and methods}

One hundred and six consecutive patients undergoing cataract surgery by the two authors who fulfilled the selection criteria were randomised to receive Ocucoat or Healonid. Patients with the following characteristics were excluded from enrolment: (1) previous ocular surgery to either eye; (2) diabetes mellitus; (3) eyes undergoing medical treatment for glaucoma; (4) previous uveitis; (5) eyes with intraoperative complications; (6) pupils which were not equally and normally reactive.

Ethics committee permission and informed consent were not sought as both viscoelastic materials were in routine use in the department. Surgery was carried out between 4 January 1994 and 18 March 1994. The study was a randomised, single centre, open, parallel group design. It was planned to enrol up to 120 patients onto the study, 60 on each treatment arm. Stratified randomisation according to a computer generated randomisation list was employed, the stratification variable was surgeon.

Pupils were assessed preoperatively by the surgeon using the slit-lamp graticule with regard to size (and compared with fellow eye), reaction, and abnormality of shape. Similar measurements were performed 4-6 weeks postoperatively by an optometrist unaware of the viscoelastic material used.

\section{SURGICAL TECHNIQUE}

All operations were performed by the two surgeons and in 102 of the 106 eyes phacoemulsification was the surgical procedure. Four eyes had extracapsular surgery. All patients had surgery under local anaesthesia using a one injection peribulbar technique. Phacoemulsification was performed through a scleral tunnel incision. The eye was opened with a $3.2 \mathrm{~mm}$ disposable keratome and viscoelastic material was used to fill the anterior chamber. Capsulorhexis was performed in all cases followed by hydrodissection. The nucleus was removed by a four quadrant cracking technique or if soft by a 'chip and flip' technique. After nuclear removal the cortex was aspirated mechanically. The infusion fluid used for both the phacoemulsification and irrigation aspiration procedure was $500 \mathrm{ml}$ balanced salt solution (BSS) with $0.5 \mathrm{ml}$ adrenaline $1: 1000$.

The capsular bag was then reinflated using the viscoelastic material and the intraocular lens inserted. The viscoelastic material was carefully aspirated and a no stitch technique was used. The conjunctiva was replaced over the wound and a subconjunctival injection of
Four eyes had extracapsular surgery. An envelope capsulotomy, hydrodissection, nuclear expression, mechanical infusion, and aspiration technique followed by lens insertion was performed; 10/0 nylon sutures were used to close the section. 


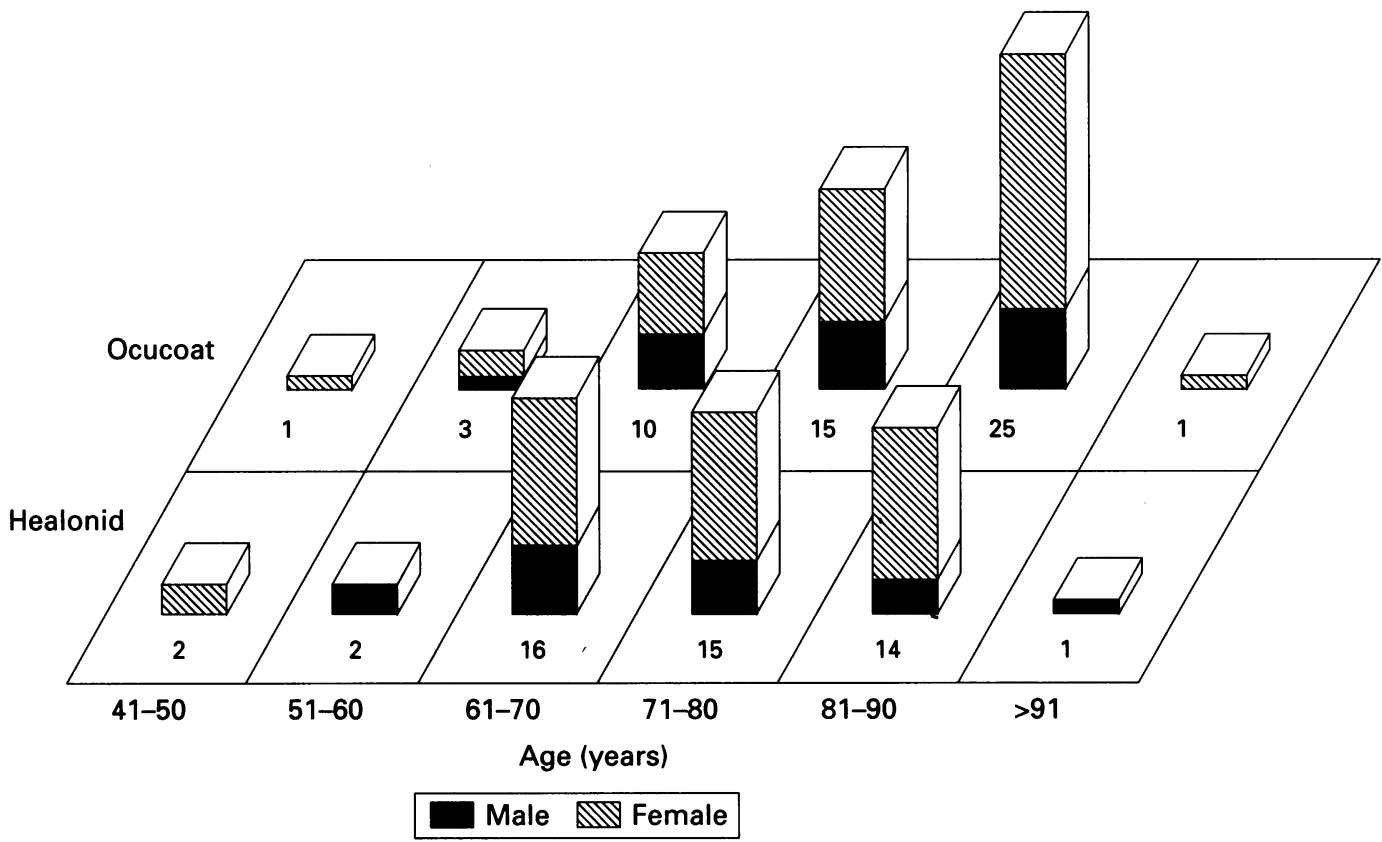

Figure 1 Viscoelastic versus pupil size study.

Table 1 Number (\%) of eligible patients by surgeon and treatment group

\begin{tabular}{llll}
\hline & \multicolumn{2}{l}{ Surgeon } & \\
\cline { 2 - 3 } Treatment & 1 & 2 & \multicolumn{1}{c}{ Total } \\
\hline Ocucoat & $28(51)$ & $27(49)$ & $55(100)$ \\
Healonid & $27(56)$ & $21(44)$ & $48(100)$ \\
Total & $55(53)$ & $48(47)$ & $103(100)$ \\
\hline
\end{tabular}

Table 2 Type of surgical technique and miochol usage

\begin{tabular}{lllrl}
\hline Treatment & $\begin{array}{l}\text { Phaco } \\
(n(\%))\end{array}$ & $\begin{array}{l}\text { Endocap } \\
(n(\%))\end{array}$ & $\begin{array}{l}\text { Total } \\
(n(\%))\end{array}$ & $\begin{array}{l}\text { Miochol used } \\
(n(\%))\end{array}$ \\
\hline Ocucoat $^{\star}$ & $51(93)$ & $\mathbf{4}(7)$ & $55(100)$ & $4(7)$ \\
Healonid & $47(100)$ & 0 & $47(100)$ & $3(6)$ \\
Total & $98(96)$ & $4(4)$ & $102(100)$ & $7(7)$ \\
\hline
\end{tabular}

^One patient from the Healonid group had missing data.

\section{STATISTICAL METHODS}

The data analysis was performed using the statistical package SAS release 6.08 . All statistical tests were assessed at the $5 \%$ level of significance. The changes in pupil size were compared between the two treatment groups using the Mann-Whitney U test.

\section{Results}

Of 106 patients enrolled into the study, 50

Table 3 Change in pupil size ( $\mathrm{mm}$ ) between baseline and 4-6 weeks postoperatively

\begin{tabular}{llllll}
\hline Treatment & No of patients & Median & Minimum & Maximum & Missing \\
\hline Ocucoat & 53 & 0.5 & -1.5 & 2 & 2 \\
Healonid & 45 & 0.5 & -1 & 2 & 3 \\
\hline
\end{tabular}

No significant difference. $p=0.69 \mathrm{Mann}-$ Whitney $U$ test.

Table 4 Change in pupil reactivity between baseline and 4-6 weeks postoperatively

\begin{tabular}{llllll}
\hline Treatment & $\begin{array}{l}\text { No change } \\
(n(\%))\end{array}$ & $\begin{array}{l}\text { Partial } \\
(n(\%))\end{array}$ & $\begin{array}{l}\text { Non-reactive } \\
(n(\%))\end{array}$ & $\begin{array}{l}\text { Total } \\
(n(\%))\end{array}$ & Missing \\
\hline Ocucoat & $51(94)$ & $2(4)$ & $1(2)$ & $54(100)$ & 1 \\
Healonid & $43(96)$ & $2(4)$ & 0 & $45(100)$ & 2 \\
Total & $94(95)$ & $4(4)$ & $1(1)$ & $99(100)$ & 3 \\
\hline
\end{tabular}

No significant difference. $p=0.99$ Fisher's exact test. were randomised to receive Healonid and 56 to receive Ocucoat. Three patients were excluded from later analysis as one patient had a partially reactive pupil preoperatively and two patients randomised to Healonid also received Ocucoat to facilitate anterior chamber maintenance (one patient in each surgeon group). The two treatment groups were comparable with respect to patient characteristics. Seventy one per cent of the patients in each group were female and the median age was 71-80 years (Fig 1). The number of patients operated on by each surgeon and the treatment they received is shown in Table 1 . There was a similar proportion of Ocucoat and Healonid patients in each surgeon group $(p=0 \cdot 73)$ (Yates's correct $\chi^{2}$ test).

The two treatment groups did not differ significantly with respect to preoperative pupil size $(\mathrm{p}=0 \cdot 22$, Mann-Whitney $U$ test). However, it was noted that patients in the surgeon 1 group had generally larger pupils than in the surgeon 2 group $(p=0.0008$, Mann-Whitney $\mathrm{U}$ test), although within each surgeon group the patients on the two treatment arms were similar in pupil size. Preoperatively all patients included in the analysis were categorised as having normal reactivity in both pupils. Miochol usage during surgery was similar in both groups with four eyes $(7 \%)$ in the Ocucoat group and three eyes $(6 \%)$ in the Healonid group receiving Miochol in the course of surgery (Table 2). The change in pupil size from baseline to 4-6 weeks after operation can be seen in Table 3. There was no significant difference between the two groups $(p=0.69$, Mann-Whitney U test). Both treatment groups had a median change of $0.5 \mathrm{~mm}-$ that is, an increase in their pupil size.

Table 4 shows the change in pupil reactivity from baseline to 4-6 weeks after operation. Two eyes (4\%) in each group had partially reactive pupils following surgery; one eye in the Ocucoat group was non-reactive following surgery. This eye, however, was noted to have 
an atrophic iris before surgery. No correlation was found between type of surgery, Miochol usage, age, sex, or ethnic origin of patient, and change in reactivity after surgery. There was no significant difference between the two treatment groups with respect to reactivity $(p=0.99$, Fisher's exact test).

\section{Discussion}

The results of this prospective randomised clinical trial show no statistical difference in pupil size or reactivity following the use of Ocucoat or Healonid in the course of cataract surgery. One pupil in the Ocucoat group was non-reactive following surgery. However, it was noted that the iris was atrophic before surgery and the pupil difficult to dilate. Miochol was not used during the surgery. Tan and Humphrey reported $16.7 \%$ of eyes were non-reactive after the use of HPMC, ${ }^{7}$ our figure is only $2 \%$. They reported no non-reactive pupils following the use of Healonid and this is similar to our findings. In our study two eyes in each group ( $4 \%$ ) were partially reactive following surgery. These figures are much lower than those of Tan and Humphrey who found $27 \cdot 8 \%$ of pupils in the HPMC group and $18.7 \%$ of pupils in the Healonid group partially reactive following surgery. ${ }^{7}$

One explanation for these differences could be in the type of surgery. Our surgery (102 out of 106 cases) was performed using phacoemulsification whereas their surgery was entirely extracapsular cataract extraction. Miochol usage in our series was similar to that of Tan and Humphrey but we found no correlation between partially or non-reactive pupils and Miochol use. We used commercially manufactured HPMC (Ocucoat) whereas it is assumed that Tan and Humphrey used pharmaceutical grade HPMC. Impurities have been found in the past in $2 \%$ HPMC from European pharmacies. ${ }^{8}$ Tan and Humphrey postulate that HPMC may have an unidentified irritating effect on the iris sphincter or its vasculature. ${ }^{7}$ During the course of phacoemulsification the viscoelastic material remains in the anterior chamber for a longer time because of the closed system. If this postulate were true then it should have an even greater effects on the pupil following phacoemulsification.

It seems likely that the higher rate of partially reactive pupils in Tan and Humphrey's study compared with the rate in our study, is a result of the difference in surgical technique employed rather than as a result of the use of viscoelastics. ${ }^{7}$

We conclude that commercially available HPMC and sodium hyaluronate have similar effects on the pupil following their use in cataract surgery.

1 Fechner PU. Methylcellulose in lens implantation. $\mathcal{f} \mathrm{Am}$ Intraocul Soc 1977; 3: 180-1.

2 Fechner PU, Fechner MU. Methylcellulose and lens implantation. Br f Ophthalmol 1983; 67: 259-63.

3 Aron Rosa D, Cohn HC, Aron J-J, Bouquety C. Methylcellulose instead of Healon in extracapsular surgery with intraocular lens implantation. Ophthalmology 1983; 90: 1235-8.

4 Storr-Paulsen A, Larsen M. Long term results of extracapsular cataract extraction with intraocular lens implantation: sodium hyaluronate $1 \%$ vs hydroxypropy methylcellulose 2\%. Acta Ophthalmol 1991; 69: 766-9

5 Chumbley LC, Morgan AM, Musallam I. Hydroxypropyl methylcellulose in extracapsular cataract surgery with intraocular lens implantation: intraocular pressure and inflammatory response. Eye 1990; 4: 121-6.

6 Sand BB, Work K, Skovbo A, Elboll P. Sodium hyaluronate and methycellulose in extracapsular cataract extraction - a controlled study of the intraocular inflammation following the peroperative use of sodium hyaluronate and methylcellulose. Acta Ophthalmol 1991; 69: 65-7.

7 Tan AKK, Humphrey RC. The fixed dilated pupil after cataract surgery - is it related to intraocular use of hypromellose? Br $\mathcal{F}$ Ophthalmol 1993; 77: 639-41.

8 Rosen ES, Gregory RPF, Barnett F. Is $2 \%$ hydroxypropyl methylcellulose a safe solution for intraoperative clinical application? F Cataract Refract Surg 1986; 12: 679-84. 